\title{
Catheter-directed middle hemorrhoidal artery embolization for life-threatening rectal bleeding
}

\author{
Mubin I Syed MD ${ }^{1}$, Najeeb Chaudhry MD ${ }^{1}$, Azim Shaikh MD ${ }^{1}$, \\ Kamal Morar MD ${ }^{1}$, Kumar Mukerjee $M^{2}{ }^{2}$, Earl Damallie $M^{3}$
}

\begin{abstract}
MI Syed, N Chaudhry, A Shaikh, K Morar, K Mukerjee, E Damallie. Catheter-directed middle hemorrhoidal artery embolization for life-threatening rectal bleeding. Can J Gastroenterol 2007;21(2):117-123.
\end{abstract}

\begin{abstract}
Over the past 10 years, arteriography has become a well-established technique for the diagnosis of acute lower gastrointestinal bleeding, but not particularly for rectal bleeding. However, to the authors' knowledge, the technique of middle hemorrhoidal artery embolization has rarely been reported in the literature. In the present report, three patients with life-threatening rectal bleeding are presented, which was controlled by superselective embolization of the middle hemorrhoidal artery or selective embolization of the internal iliac artery as a last resort.
\end{abstract}

Key Words: Embolization; Hemorrhage; Hemorrhoid; Intrarectal bleeding; Middle hemorrhoidal artery; Prostate biopsy; Prostate cancer; Rectal bleeding

$\mathrm{R}^{\mathrm{e}}$ ectal bleeding represents approximately $9 \%$ to $10 \%$ of all R.auses of lower gastrointestinal bleeding (1). Over the past 10 years, arteriography has become a well-established technique for the diagnosis of acute lower gastrointestinal bleeding, but not particularly for rectal bleeding. Specifically, there have been arteriography documentations of the inferior mesenteric artery, including selective superior hemorrhoidal artery embolization (2-6). However, to the authors' knowledge, the selective embolization of the middle hemorrhoidal artery has rarely been reported in the literature $(7,8)$. In the present report, three patients are presented with lifethreatening rectal bleeding, which was controlled by superselective embolization of the middle hemorrhoidal artery or selective embolization of the internal iliac artery as a last resort. Approval from Mercy Medical Center's (USA) Institutional Review Board was not required for retrospective reviews.

\section{CASE PRESENTATIONS}

Case 1

A 67-year-old Caucasian man was admitted to hospital with chief complaints of chest pain and osteomyelitis. While in the hospital, the patient became hemodynamically unstable due to rectal bleeding, which was noted due to a drop in blood pressure and hemoglobin levels. Hemodynamic status was maintained using vasopressors, fresh frozen plasma and packed red blood cells. A nuclear medicine-tagged red blood cell scan was

\author{
Embolisation de l'artère hémorrhoïdale \\ médiane dirigée par cathéter pour une \\ hémorragie rectale gravissime
}

\begin{abstract}
Depuis une dizaine d'années, l'artériographie est devenue une technique reconnue pour le diagnostic de l'hémorragie digestive basse, mais moins reconnue dans les cas d'hémorragie rectale. Par contre, à la connaissance des auteurs, la technique d'embolisation de l'artère hémorrhoïdale médiane n'avait encore jamais été mentionnée dans la littérature. Le présent rapport fait état de trois cas présentant une hémorragie rectale gravissime qui a pu être maîtrisée par l'embolisation supersélective de l'artère hémorrhoïdale médiane ou l'embolisation sélective de l'artère iliaque interne, en dernier ressort.
\end{abstract}

\footnotetext{
${ }^{1}$ Department of Interventional Radiology; ${ }^{2}$ Department of Gastroenterology; ${ }^{3}$ Department of Colorectal Surgery, Mercy Medical Center, Springfield, Ohio, USA

Correspondence and reprints: Dr Mubin I Syed, Dayton Interventional Radiology, 3075 Governor's Place Boulevard, Suite \#120, Dayton, Ohio, USA. Telephone 937-215-0878, fax 937-424-2581,e-mail mubinsyed@aol.com

Received for publication November 28, 2005. Accepted April 17, 2006
} 


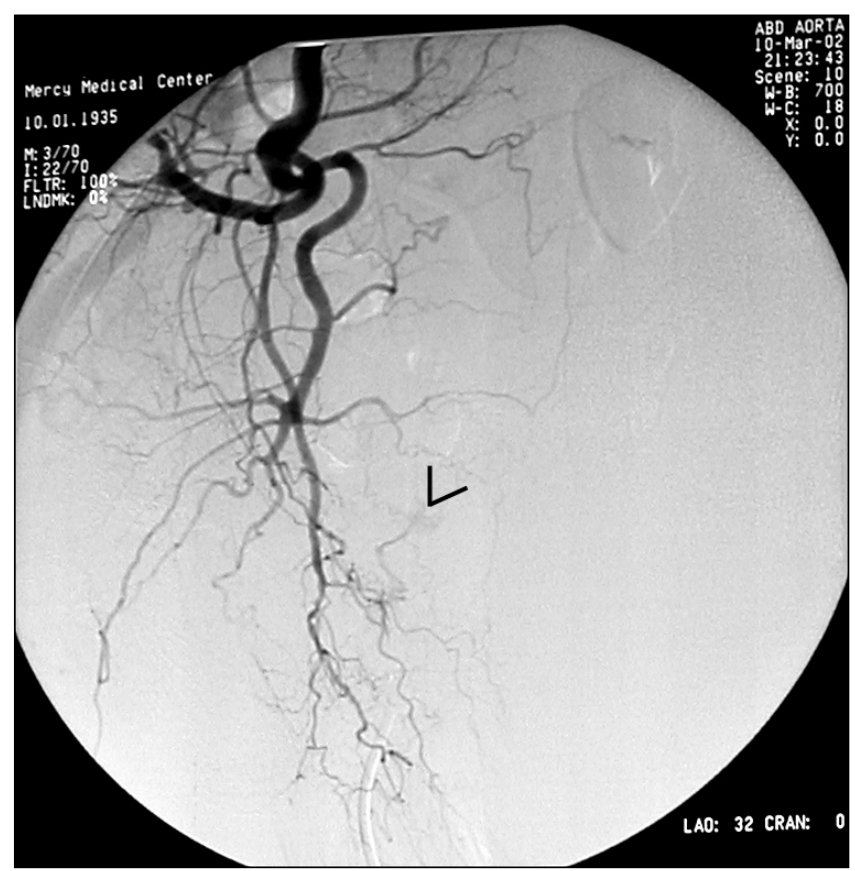

Figure 1) Case 1 - Preembolization arteriogram of the right internal iliac artery showing the extravasation site (arrowhead)

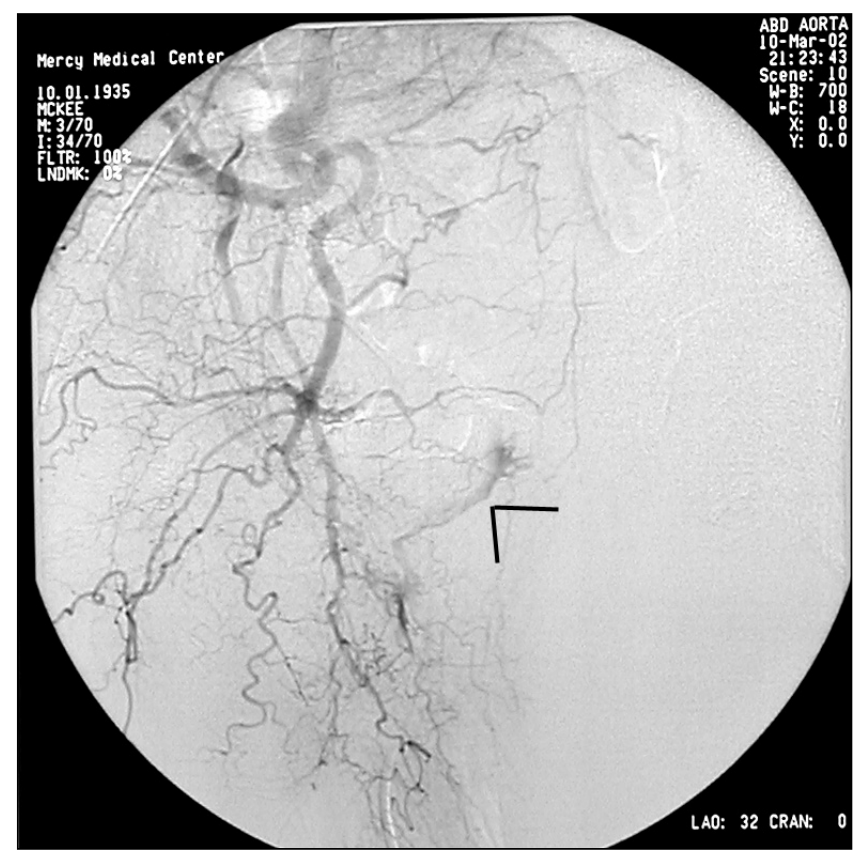

Figure 2) Case 1 - Delayed preembolization arteriogram of the same right internal iliac artery showing the extravasation site (arrowhead), which is now much easier to see

particles (Cook Inc, USA) of $355 \mu \mathrm{m}$ to $500 \mu \mathrm{m}$. The postembolization arteriogram revealed that the bleeding was no longer visible (Figure 4). The catheter was then withdrawn into the right internal iliac artery. Hand injection demonstrated filling of all the arterial branches except the right middle hemorrhoidal artery. The patient tolerated the entire procedure without any immediate complications. There was complete cessation of the patient's active rectal bleeding following the procedure. Altogether, the patient required seven units of packed red blood cells from the time active bleeding was identified to postembolization, when the patient's hemoglobin

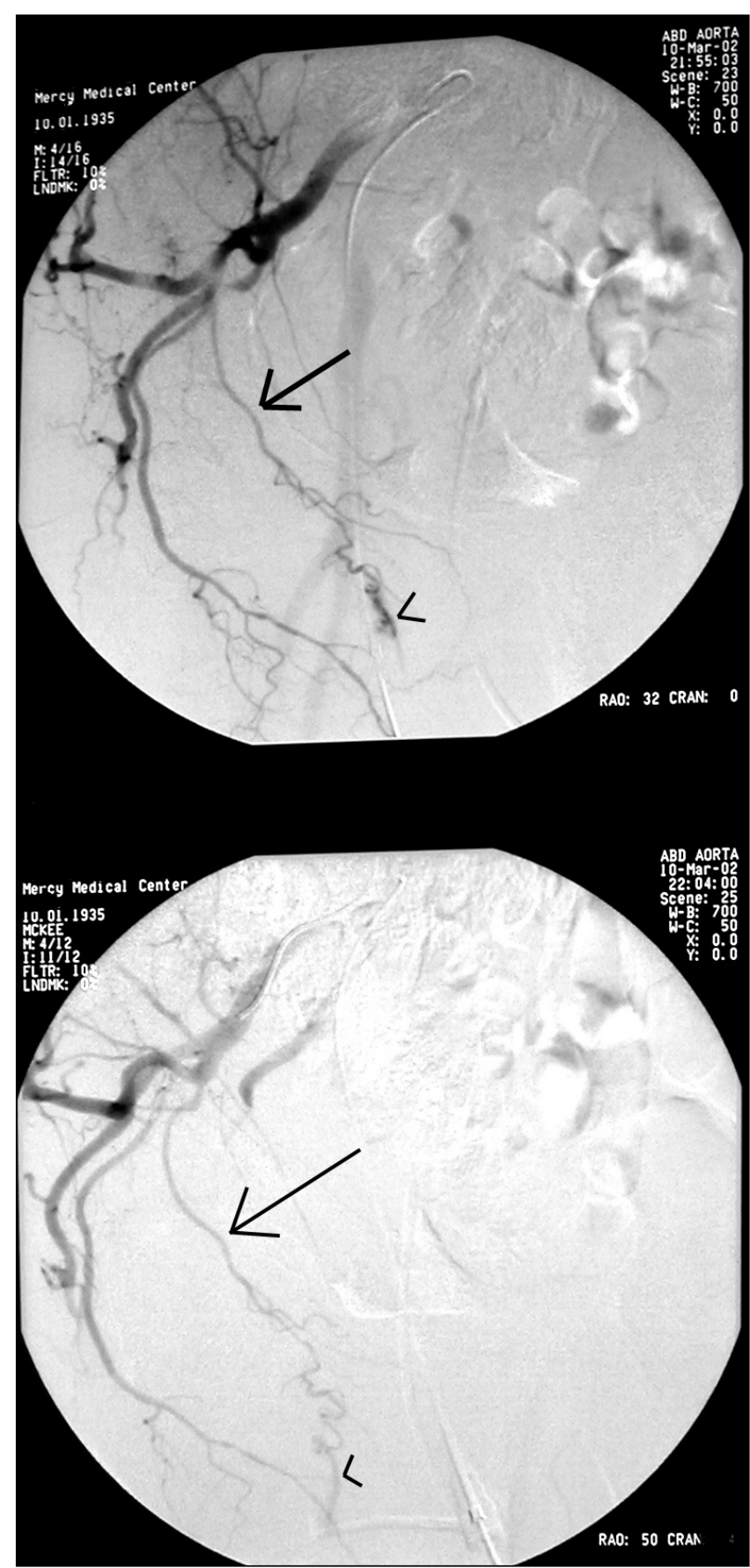

Figure 3) Case 1 - Preembolization arteriogram of the same right internal iliac artery showing the extravasation site (arrrowhead) and the middle hemmorhoidal artery (arrow) through a different projection

levels stabilized - a total time period of four days. The patient was followed up for 3.5 years postprocedure, and he remains asymptomatic.

Case 2

A 75-year-old Caucasian man, with a two-day history of hematochezia up to seven times a day, was admitted to the emergency room after a transrectal prostatic biopsy had been performed seven days before admission. He complained of lightheadedness and one to two episodes of syncope on the day of admission. The patient also complained of feeling too weak 


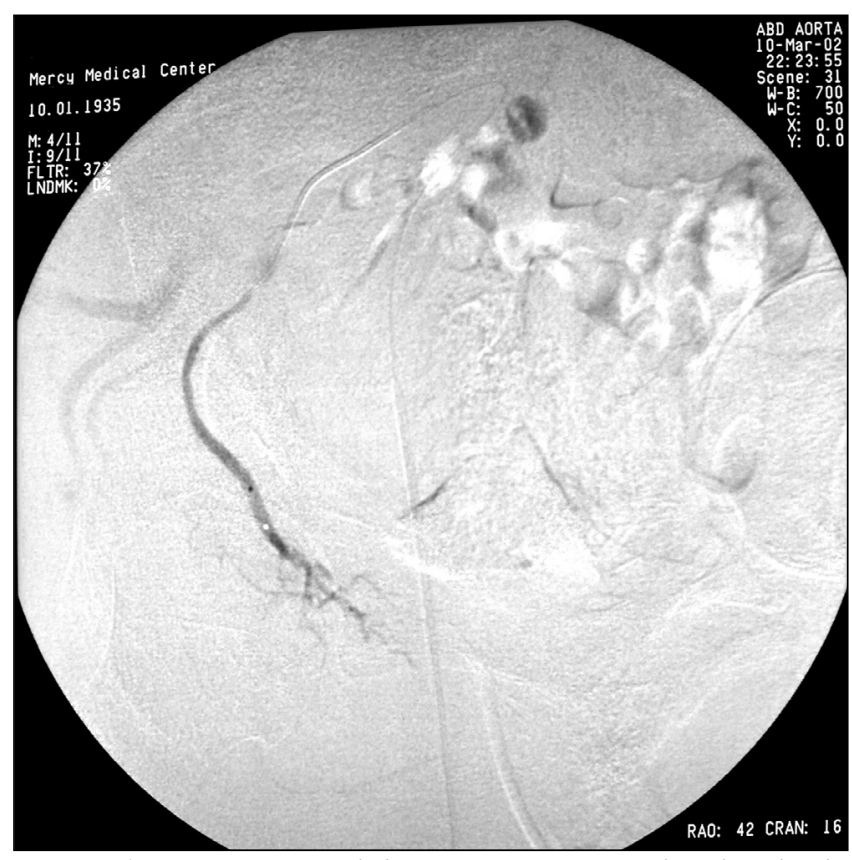

Figure 4) Case 1 - Postembolization arteriogram of the selected right middle hemmorhoidal artery. The extravasation site is no longer seen

to stand up. He demonstrated orthostatic hypotension, and his hemoglobin level dropped to $9.0 \mathrm{~g} / \mathrm{dL}$ (normal range $12.0 \mathrm{~g} / \mathrm{dL}$ to $15.6 \mathrm{~g} / \mathrm{dL}$ ). The patient was admitted to the intensive care unit where he lost an additional $1500 \mathrm{~mL}$ of bright red blood through the rectum. However, he was stabilized with a transfusion of four units of packed red blood cells and fluid resuscitation. In addition, a nuclear medicine-tagged red blood cell scan (Figure 5) was performed to localize the bleeding and for possible intervention. Interventional radiology was consulted by general surgery and gastroenterology for visceral arteriography, with possible embolization of the bleeding artery. The gastroenterologist on the case thought that the patient was bleeding too massively for endoscopic treatment. After obtaining informed consent and using standard catheter and wire guide techniques, an abdominal arteriogram was performed, which showed a severely stenosed inferior mesenteric artery, preventing selective catheterization. The left internal iliac arteriogram demonstrated no extravasations of contrast to suggest active bleeding. Next, the right internal iliac artery was selected using a 4-French Simmons catheter (Cordis Co, USA) and Bentson guide wire (Cook Inc, USA). A subsequent arteriogram in various projections demonstrated active, brisk extravasations from one of the distal branches of the middle hemorrhoidal artery at the level of the prostate gland (Figure 6). The middle hemorrhoidal artery was selected using a Renegade microcatheter (Boston Scientific Inc, USA) and Transcend $0.35 \mathrm{~mm}$ guide wire (Boston Scientific Inc, USA). A selective middle hemorrhoidal arteriogram showed extravasation from the site of the distal artery (Figure 7). Therefore, the vessel was embolized using one vial of $355 \mu \mathrm{m}$ to $500 \mu \mathrm{m}$ polyvinyl alcohol particles with cessation of extravasations and slowing of flow within the right middle hemorrhoidal artery. This was confirmed on the postembolization arteriogram of the selective right internal iliac artery (Figure 8). Although the bleeding had stopped, the patient required two more units of packed red blood cells to stabilize

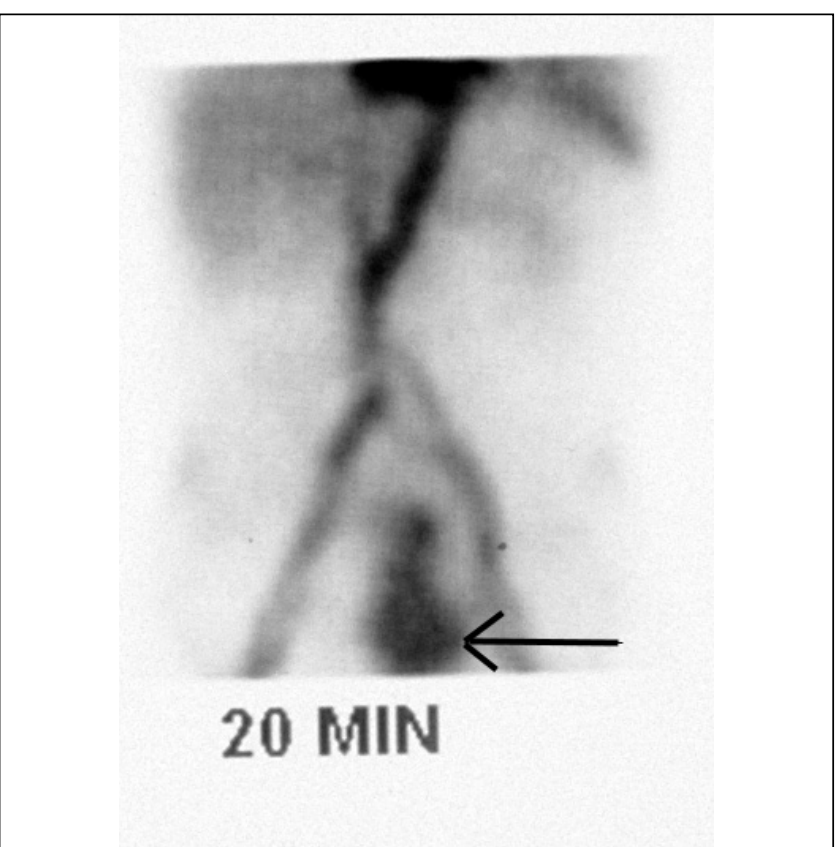

Figure 5) Case 2 - Nuclear medicine-tagged red blood cell scan showing the bleeding site from rectum (arrow)

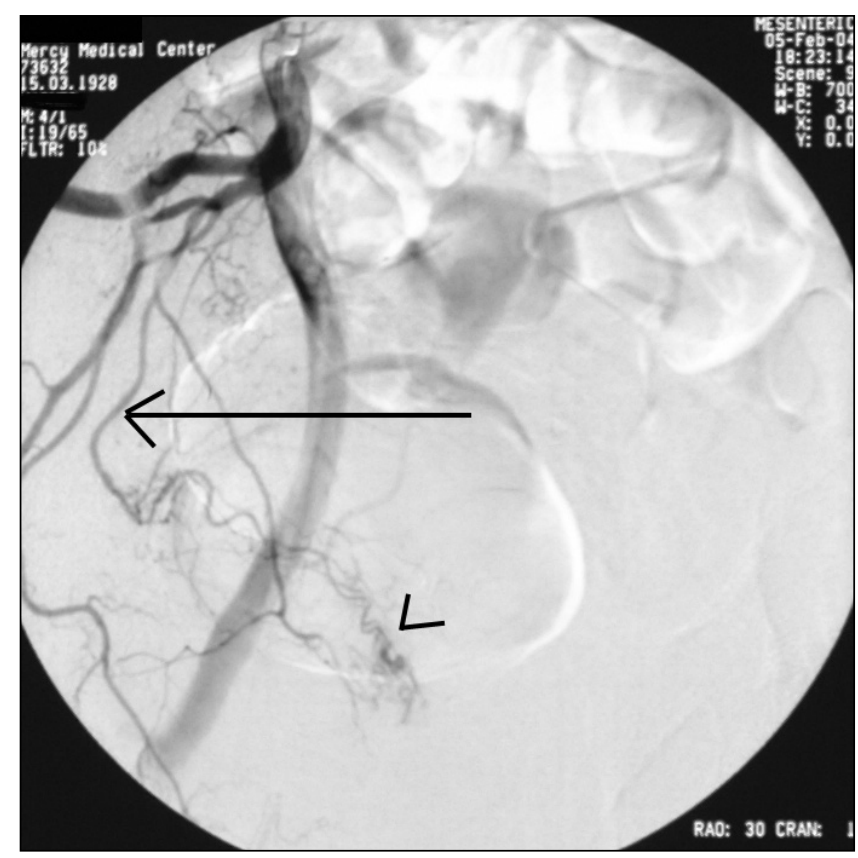

Figure 6) Case 2 - Preembolization arteriogram of the right internal iliac artery showing the extravasation site (arrowhead) and the middle hemorrhoidal artery (arrow)

his hemoglobin levels two days later, despite no further indication of bleeding. The patient required a total transfusion of six units of packed red blood cells. The patient has been followed up over the past 1.5 years and is doing well.

\section{Case 3}

A 58-year-old male physician, with a known history of metastatic prostate adenocarcinoma with anterior invasion of the rectum, recent radiation therapy and transurethral resection of the prostate, presented to the emergency room with intermittent 


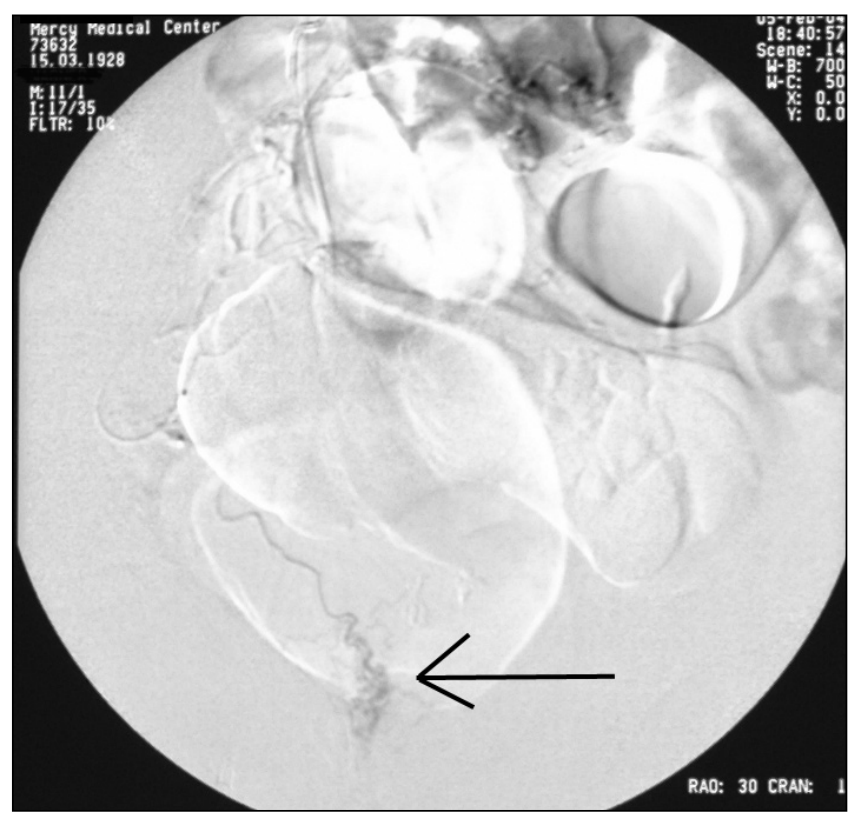

Figure 7) Case 2 - A selective middle hemorrhoidal arteriogram showing extravasation (arrow) from the site of the distal artery

lower gastrointestinal bleeding, over the past four weeks. He had had several blood transfusions, including two units of packed red blood cells, approximately three days before admission due to rectal bleeding. However, the patient reported more bleeding and had become hemodynamically unstable. The patient's hemoglobin level had dropped from $9.3 \mathrm{~g} / \mathrm{dL}$ to $6.3 \mathrm{~g} / \mathrm{dL}$ over $48 \mathrm{~h}$. The patient was evaluated by surgery and gastroenterology, and was admitted to the intensive care unit where three units of packed red blood cells were transfused and the patient responded to fluid resuscitation. Surgery was considered high risk due to his recent radiation therapy. Initially, it was thought that the bleeding was too massive to allow endoscopic treatment. Therefore, the patient underwent selective bilateral internal iliac arteriography, which demonstrated no active bleeding. The patient underwent superselective empirical embolization of his bilateral obturator arteries because the middle hemorrhoidal arteries could not be identified. The embolization was performed using $500 \mu \mathrm{m}$ to $700 \mu \mathrm{m}$ polyvinyl alcohol microspheres (Contour SE microspheres, Boston Scientific Inc, USA). The patient was stable, and arteriograms performed in various projections showed no signs of active bleeding. At that point, the patient reported the cessation of his urge to defecate or any sensation of rectal fullness, which had previously indicated acute rectal bleeding. However, the patient started to rebleed the next day. Therefore, empirical embolization of the internal iliac artery was carried out using Gelfoam slurry (Pharmacia \& Upjohn Inc, USA). This occluded the distal portion of each major branch of the internal iliac artery, although the main trunk and its major branches were patent. Later, the patient stopped bleeding and there was no complication from these procedures. He required a total transfusion of eight units of packed red blood cells. He lived for approximately nine months postprocedure.

\section{DISCUSSION}

Rectal bleeding represents $9 \%$ to $11 \%$ of all causes of lower gastrointestinal bleeding. The most common causes of massive rectal bleeding include hemorrhoids, anal fissures and fistulas

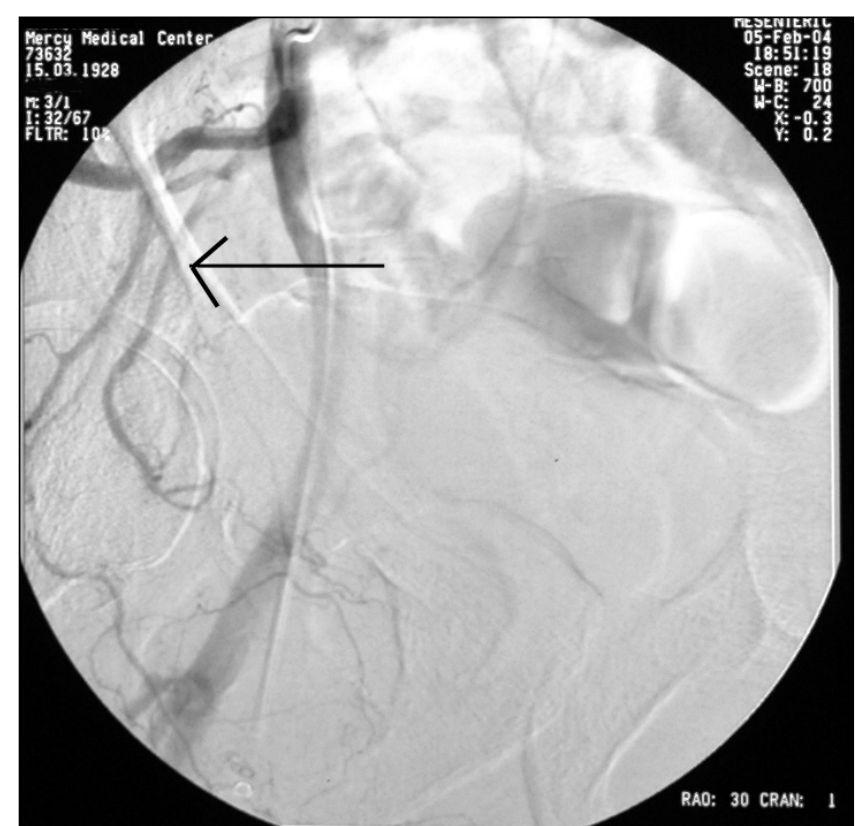

Figure 8) Case 2 - Postembolizaton arteriogram of the right internal iliac artery showing the right middle hemorrhoidal artery (arrow). Note the lack of the extravasation site

in ano. More unusual causes of bleeding include solitary rectal ulcer syndrome, radiation proctitis and prostate biopsy (9). As seen in the three cases presented, the technique of superselective embolization offers a viable treatment option independent of etiology. This is because the treatment is based on the occlusion of the arterial blood supply to the lesion, rather than the characteristics of the lesion.

The primary objective in managing a patient with massive rectal bleeding is hemodynamic stabilization. This can be accomplished through the use of large-bore intravenous lines and volume repletion through the use of fresh frozen plasma and packed red blood cells. It may be necessary to insert a Foley catheter, because it can help to monitor urine output and prevent obscuring of the angiographic field by a contrast-filled bladder. Arterial pressure monitoring may be required in patients with a persistently unstable condition. Once measures to stabilize the patient have been satisfactorily instituted, it is reasonable to proceed with arteriography. This was the situation in all our patients. Finally, anesthesiology support may be helpful for the borderline hemodynamically stable patient.

The vascular blood supply to the rectum is from a relatively rich anastomotic supply, ie, from the inferior mesentery artery via the superior hemorrhoidal artery (superior aspect of rectum), and the middle and inferior hemorrhoidal arteries that arise as branches of the internal iliac artery and supply the lower one-half to two-thirds of the rectum (10). The collateral blood allows a safety margin during embolization to prevent ischemia or infarction that can occur during colonic or small bowel embolization (3). The right and left inferior hemorrhoidal arteries are distal branches of the internal pudendal arteries within the ischiorectal fossa. These arteries have an extensive anastomotic network within the wall of the rectum.

The goal of embolization therapy should be to decrease the pulse pressure at the bleeding site to allow for hemostasis (11). However, to reduce the area at risk for ischemia, the most distal site should be chosen for embolization $(3,4)$. Thus, 
superselective embolization of the middle hemorrhoidal artery theoretically reduces the risk of ischemic complication.

In retrospect, Goldberger and Bookstein (11) reported on one of the first cases of arterial embolization in 1977 for the treatment of acute lower gastrointestinal hemorrhage, and in 1978, Bookstein et al (12) reported further experience with this technique. These studies reported a total of seven patients undergoing transcatheter embolizations of proximal branches of the mesenteric arteries. However, there was no evidence of post-transcatheter embolization infarction occurring in these patients. Since then, a meta-analysis of 144 lower gastrointestinal hemorrhage patients treated with superselective microcoil embolization demonstrated no major ischemic complications (13).

The choice of occlusive agents used is dependent on the location of the transcatheter embolization and the comfort of the operator. In recent years, microcoils have gained favour over polyvinyl alcohol particles for lower gastrointestinal embolization of the colon for a variety of reasons, including accurate sizing for the target vessel, quantitatively controlled delivery, precise deployment due to radiopacity and facilitation of accurate surgical incision, if necessary (13). In these cases, the target vessel (middle hemorrhoidal artery) is so small that deployment of microcoils would be technically difficult. Pichon et al (7) demonstrated the safety and efficacy of using particles for embolization in this artery. Morar et al (8) also reported the safety and efficacy of the use of particles for embolization in this artery. The safety of polyvinyl alcohol particle size $(190 \mu \mathrm{m}$ to $500 \mu \mathrm{m})$ has been demonstrated in many cases, which have shown that the use of these particles does not result in bowel infarction or clinically significant mucosal ischemia $(3,4)$. Therefore, the particle size of $355 \mu \mathrm{m}$ to $500 \mu \mathrm{m}$ or larger that we used is within the established standard of treatment for lower gastrointestinal hemorrhage. It is thought that the rectum, with its numerous anastomotic connections, is much less susceptible to ischemia than the colon. Gelfoam has the advantage of being a temporary occlusive agent when used to embolize, nonselectively, a large arterial bed such as the internal iliac artery (seen in patient 3 ).

The clinical management of life-threatening rectal bleeding continues to remain the domain of either the gastroenterologist or surgeon. Two different approaches could be used for the treatment of active lower gastrointestinal bleeding. One algorithm is the 'standard care algorithm' involving interventional radiology as described by Green et al (14), and the other algorithm involves urgent colonoscopy. This recently published, randomized controlled trial (14) suggested that both approaches had similar outcomes with respect to important end points. The study concluded that the algorithm used should be based on individual experience and local expertise. However, this study has been critiqued by Jensen (15), who expressed concern with the conclusions of the study. He suggested that the study was flawed due to the lack of triage of patients by stigmata of hemorrhage, fair or poor colonic preparation in $64 \%$ of patients, lack of operator experience in urgent colonoscopy due to the novelty of the technique at the time the study was performed, high rebleeding rates in the urgent colonoscopy group and premature termination of the trial. The trial was completed more than 10 years ago, and advances in colonoscopic expertise have occurred.

Conversely, the other issue is that the study was performed 10 years ago, with vasopressin infusion as the therapeutic

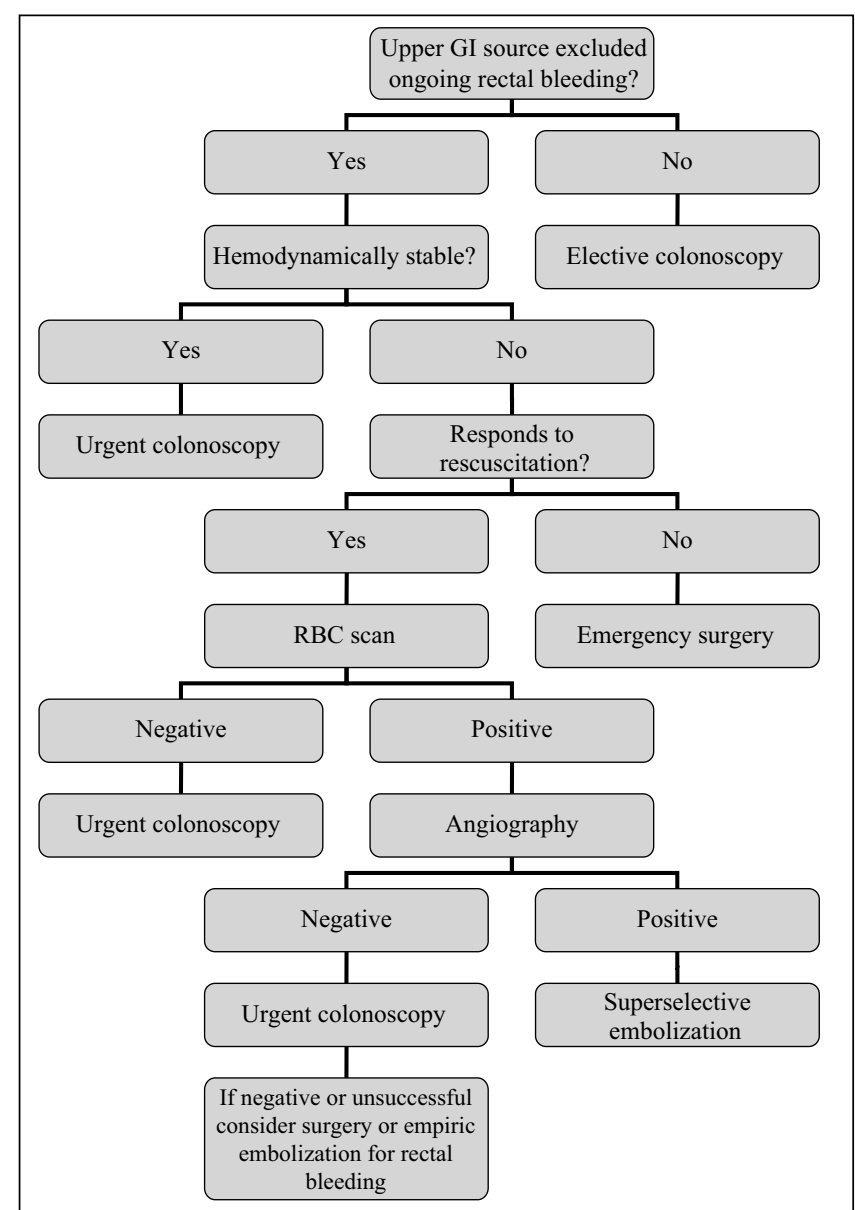

Figure 9) Proposed algorithm for the treatment of rectal bleeding. GI Gastrointestinal; RBC Red blood cell

option during angiography, whereas the current standard in interventional radiology is superselective embolization. In fact, in the surgical literature, Neuman et al (16) recently proposed superselective catheter embolization as a first-line therapy for lower gastrointestinal bleeding. Specifically, this technique should be offered in severe, active lower gastrointestinal bleeding when the patient responds to initial fluid resuscitation and the bleeding scan is positive. Strate and Syngal (17) analyzed which factors favoured referral for radiological interventions versus endoscopic therapy. They found that more severe bleeding favoured radiological intervention, whereas logistical factors and a likelihood of a localized source of bleeding led to early colonoscopy. Green and Rockey (18) suggested that in the setting of aggressive or recurrent bleeding, it is critical for the practitioner to judge when angiography and surgery are necessary. To unify these different approaches into one algorithm, we propose the algorithm shown in Figure 9.

Urgent colonoscopy after rapid purge is of proven value in the diagnosis and treatment of the most common sources of hematochezia, including angiomata and diverticula $(1,19)$. It has been widely reported that urgent colonoscopy is safe, and in a high proportion of cases, it results in specific diagnosis and treatment $(18,19)$. One of the advantages of purge colonoscopy is that it can be performed at the bedside versus the angiography suite for arterial embolization. Also, purge colonoscopy has none of the rare risks of angiography, such as the potential of adverse contrast reactions, nephrotoxicity, 
hematomas or pseudoaneurysms, and vessel dissection or perforation. Furthermore, there is no risk of bowel ischemia, which can occur with embolization of the colon.

However, visceral arteriography has a well-defined diagnostic and therapeutic role in the management of patients with gastrointestinal bleeding. It is valuable in identifying the specific site of bleeding and in achieving hemostasis using either arterial catheter infusion of vasopressin or transcatheterdirected embolization (20). Radiological treatment using selective embolization has gained widespread acceptance for upper gastrointestinal hemorrhage, but also more recently, for lower gastrointestinal bleeding due to advancements in technology with the development of better microcatheters $(3,5,13,21-23)$. The advancement in microcatheters has allowed better positioning and thereby selective embolization of the artery of choice $(3-5,21-23)$. The advantage of this technique is that it does not require time for bowel preparation, unlike urgent colonoscopy, and can be used to localize and treat bleeding throughout the gastrointestinal tract.

However, reports of catheter-directed intervention for rectal bleeding via the middle hemorrhoidal artery have been rare, ie, one to two patient case reports $(7,8)$. Increasing evidence supports the theory that superselective embolization may actually be more efficacious in reducing complications $(2-5,21-23)$. The main rationale for the superselection of the middle hemorrhoidal artery in the present cases is both its theoretical improved safety and higher efficacy compared with nonselective embolization.

We admit that as the first procedure, empirical embolization of the obturator arteries may be considered contentious in patient 3. Surgery was not an option for this patient and a trial of embolization was seen as the only option for active management. Again, the risk of ischemia due to the collateral circulation in this vascular distribution would be expected to be less than that in the colon. Provocative angiography with heparin, vasodilators and thrombolytics has been attempted in small case series, but complications have been reported and definitive safety profiles have yet to be established (24-26). Therefore, in this patient, we chose to nonselectively embolize the internal iliac arteries. Complete embolization of the internal iliac arteries has been accepted for the treatment of uncontrolled pelvic bleeding. Similarly, it has been described

\section{REFERENCES}

1. Lee EW, Laberge JM. Differential diagnosis of gastrointestinal bleeding. Tech Vasc Interv Radiol 2004;7:112-22.

2. Kramer SC, Gorich J, Rilinger, N et al. Embolization for gastrointestinal hemorrhages. Eur Radiol 2000;10:802-5.

3. Guy GE, Shetty PC, Sharma RP, Burke MW, Burke TH. Acute lower gastrointestinal hemorrhage: Treatment by superselective embolization with polyvinyl alcohol particles. AJR Am J Roentgenol 1992;159:521-6.

4. Bandi R, Shetty PC, Sharma RP, Burke TH, Burke MW, Kastan D. Superselective arterial embolization for the treatment of lower gastrointestinal hemorrhage. J Vasc Interv Radiol 2001;12:1399-405.

5. Ledermann HP, Schoch E, Jost R, Decurtins M, Zollikofer CL.

Superselective coil embolization in acute gastrointestinal hemorrhage: Personal experience in 10 patients and review of the literature. J Vasc Interv Radiol 1998;9:753-60.

6. Lee JH, Lee KH, Chung WS, Hur J, Won JY, Lee do Y. Transcatheter embolization of the middle sacral artery: Collateral feeder in recurrent rectal bleeding. AJR Am J Roentgenol 2004;182:1055-7.

7. Pichon N, Francois B, Pichon-Lefievre F, Mathonnet M, Maubon A, Vignon P. Embolization of rectal arteries: An alternative treatment for hemorrhagic shock induced by traumatic intrarectal hemorrhage. Cardiovasc Intervent Radiol 2005;28:515-7. for rectal bleeding in one patient by Chuang et al (27) in 1979. This was the justification for embolization in patient 3 when superselective embolization failed.

Interventional radiologists are very familiar with embolization for rectal bleeding, but it is usually via the superior hemorrhoidal artery branch of the inferior mesenteric artery $(2-6)$. What is relatively unique about the present cases is that the source of bleeding and vessels embolized were from the internal iliac artery distribution via the middle rectal artery. The middle and inferior hemorrhoidal arteries are typically ignored as sources of bleeding, probably because lower rectal bleeding sites are generally managed with local surgery or endoscopy. Even in institutions in which arteriography for gastrointestinal bleeding is actively practiced, it is not part of the standard routine to study the internal iliac distribution $(1,28)$.

The technique of superselective embolization of the middle hemorrhoidal artery has been recently described in two patients by Pichon et al (7). We have also previously reported case 1 as an example of selective embolization via the middle hemorrhoidal artery approach for an internal hemorrhoid (8). However, we do not dispute that even in a high-risk patient such as ours, a transanal surgical approach using local or epidural analgesia would likely have succeeded. This approach, however, would have been more challenging in a patient whose hemorrhoid was more proximally located, ie, $10 \mathrm{~cm}$ from the anal verge, as in our patient. Similarly, this same embolization technique can be effective for the lifethreatening hemorrhage from prostate biopsy, as in our second patient, in particular when tampon insertion fails (29). Again, we concede that an endoscopic band ligation could have been equally as successful (30). Other selective embolizations have included the inferior gluteal artery and the middle sacral artery for life-threatening rectal bleeding (6,31). Finally, when this superselective technique of embolization fails, a nonselective (Gelfoam slurry) embolization of the internal iliac artery may be helpful.

We believe that this technique may be helpful in a desperate clinical situation depending on local expertise. Catheterdirected treatment could provide a minimally invasive, safe and timely treatment for life-threatening rectal bleeding in selected patients.

8. Morar KN, Syed MI, Patel JK, Shaikh A. Embolization of middle hemorrhoidal artery in the management of life-threatening rectal bleeding. Cardiovasc Intervent Radiol 2006;29:128-9.

9. Cagir B, Cirincione E. Lower Gastrointestinal Bleeding: Surgical Perspective. <http://www.emedicine.com/med/topic2818.htm> (Version current at January 12, 2007).

10. Moore KL. Clinically Oriented Anatomy, 2nd edn. Minnesota: Lippincott Williams \& Wilkins, 1985.

11. Goldberger LE, Bookstein JJ. Transcatheter embolization for treatment of diverticular hemorrhage. Radiology 1977;122:613-7.

12. Bookstein JJ, Naderi MJ, Walter JF. Transcatheter embolization for lower gastrointestinal bleeding. Radiology 1978;127:345-9.

13. Kuo WT, Lee DE, Saad WE, Patel N, Sahler LG, Waldman DL. Superselective microcoil embolization for the treatment of lower gastrointestinal hemorrhage. J Vasc Interv Radiol 2003;14:1503-9.

14. Green BT, Rockey DC, Portwood G, et al. Urgent colonoscopy for evaluation and management of acute lower gastrointestinal hemorrhage: A randomized controlled trial. Am J Gastroenterol 2005;100:2395-402.

15. Jensen DM. Management of patients with severe hematochezia - With all current evidence available. Am J Gastroenterol 2005;100:2403-6. 
16. Neuman HB, Zarzaur BL, Meyer AA, Cairns BA, Rich PB. Superselective catheterization and embolization as first-line therapy for lower gastrointestinal bleeding. Am Surg 2005;71:539-44; discussion 544-5.

17. Strate LL, Syngal S. Predictors of utilization of early colonoscopy vs radiography for severe lower intestinal bleeding. Gastrointest Endosc 2005;61:46-52.

18. Green BT, Rockey DC. Lower gastrointestinal bleeding Management. Gastroenterol Clin North Am 2005;34:665-78

19. Jensen DM, Machicado GA, Jutabha R, Kovacs TO. Urgent colonoscopy for the diagnosis and treatment of severe diverticular hemorrhage. N Engl J Med 2000;342:78-82.

20. Eckstein MR, Athanasoulis CA. Gastrointestinal bleeding. An angiographic perspective. Surg Clin North Am 1984;64:37-51.

21. Evangelista PT, Hallisey MJ. Transcatheter embolization for acute lower gastrointestinal hemorrhage. J Vasc Interv Radiol 2000;11:601-6.

22. Gordon RL, Ahl KL, Kerlan RK, et al. Selective arterial embolization for the control of lower gastrointestinal bleeding. Am J Surg 1997; 174:24-8

23. Peck DJ, McLoughlin RF, Hughson MN, Rankin RN. Percutaneous embolotherapy of lower gastrointestinal hemorrhage. J Vasc Interv Radiol 1998;9:747-51.
24. Koval G, Benner KG, Rosch J, Kozak BE. Aggressive angiographic diagnosis in acute lower gastrointestinal hemorrhage. Dig Dis Sci 1987;32:248-53

25. Ryan JM, Key SM, Dumbleton SA, Smith TP. Nonlocalized lower gastrointestinal bleeding: Provocative bleeding studies with intraarterial tPA, heparin, and tolazoline. J Vasc Interv Radiol 2001;12:1273-7.

26. Bloomfeld RS, Smith TP, Schneider AM, Rockey DC. Provocative angiography in patients with gastrointestinal hemorrhage of obscure origin. Am J Gastroenterol 2000;95:2807-12.

27. Chuang VP, Wallace S, Zornoza J, Davis LJ. Transcatheter arterial occlusion in the management of rectosigmoidal bleeding. Radiology 1979;133:605-9.

28. Nemcek AA Jr. Transcatheter therapy for lower gastrointestinal bleeding. Tech Vasc Interv Radiol 2000;3:139-46.

29. Maatman TJ, Bigham D, Stirling B. Simplified management of post-prostate biopsy rectal bleeding. Urology 2002;60:508.

30. Strate LL, O'Leary MP, Carr-Locke DL. Endoscopic treatment of massive rectal bleeding following prostate needle biopsy. Endoscopy 2001;33:981-4.

31. Scotti DM, Leiber C, Hur G, Marks GJ. Ruptured inferior gluteal artery aneurysm with exsanguinating rectal hemorrhage controlled by transcatheter coil embolization. Dis Colon Rectum 1980;23:313-7. 


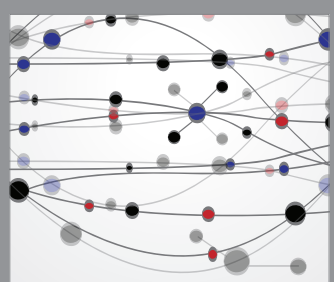

The Scientific World Journal
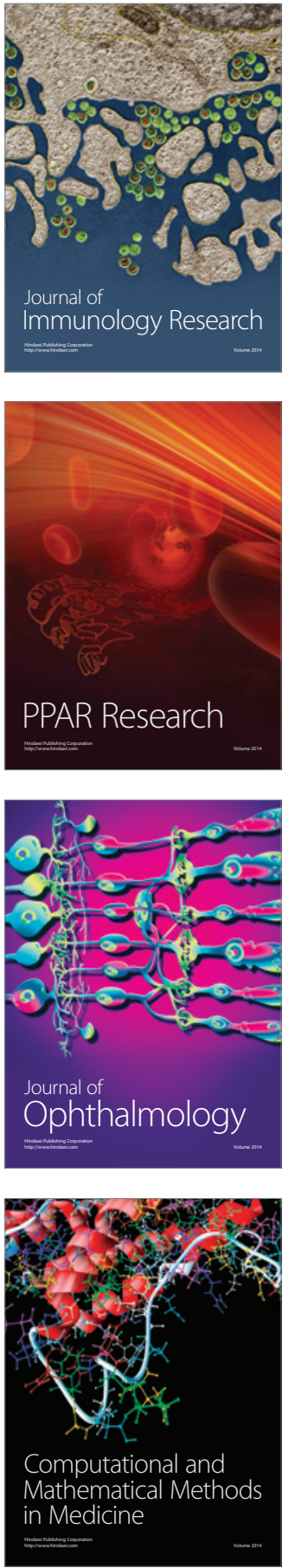

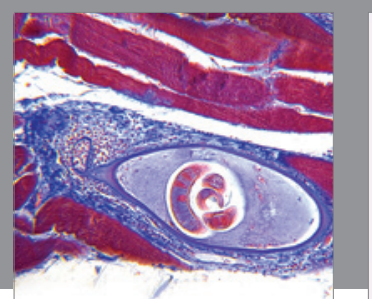

Gastroenterology Research and Practice

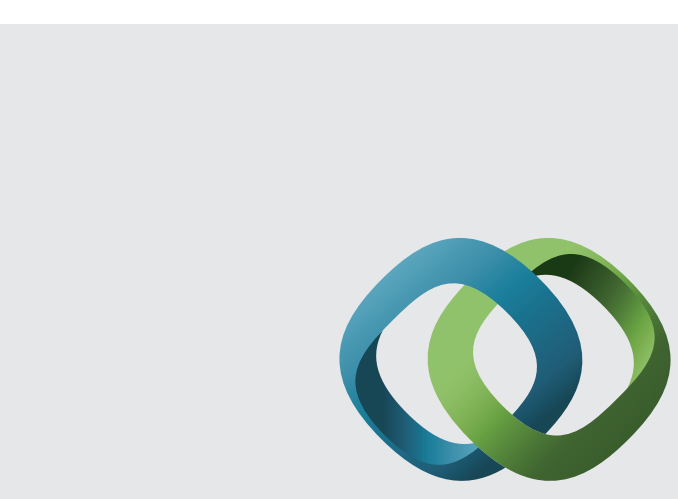

\section{Hindawi}

Submit your manuscripts at

http://www.hindawi.com
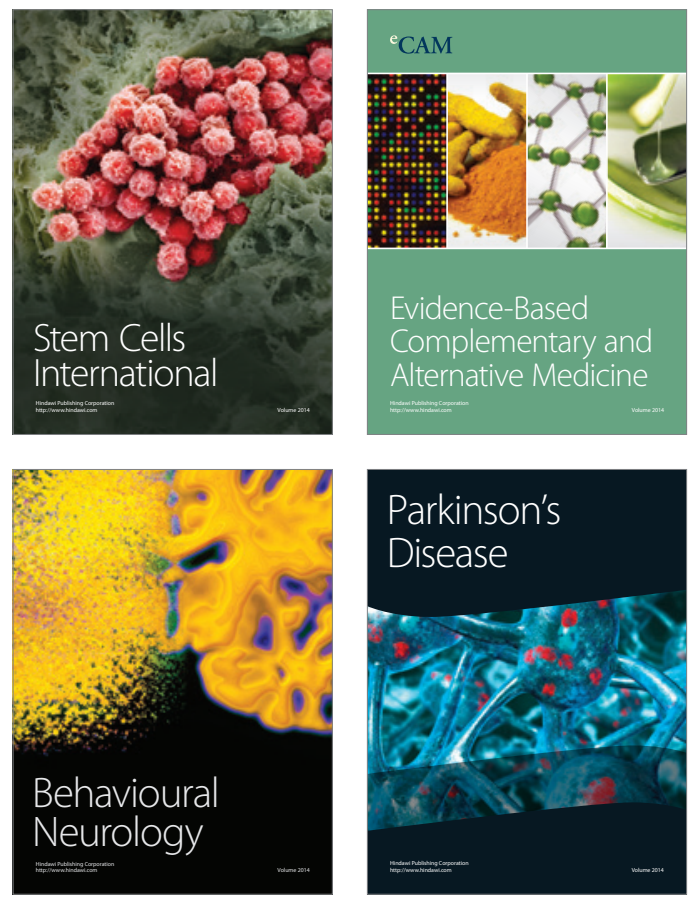
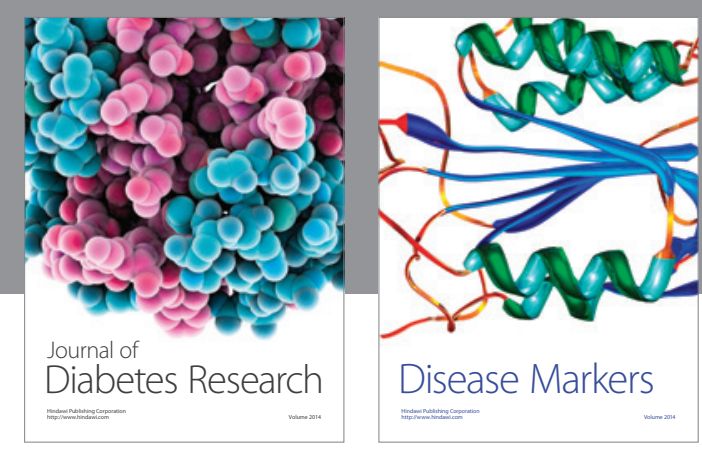

Disease Markers
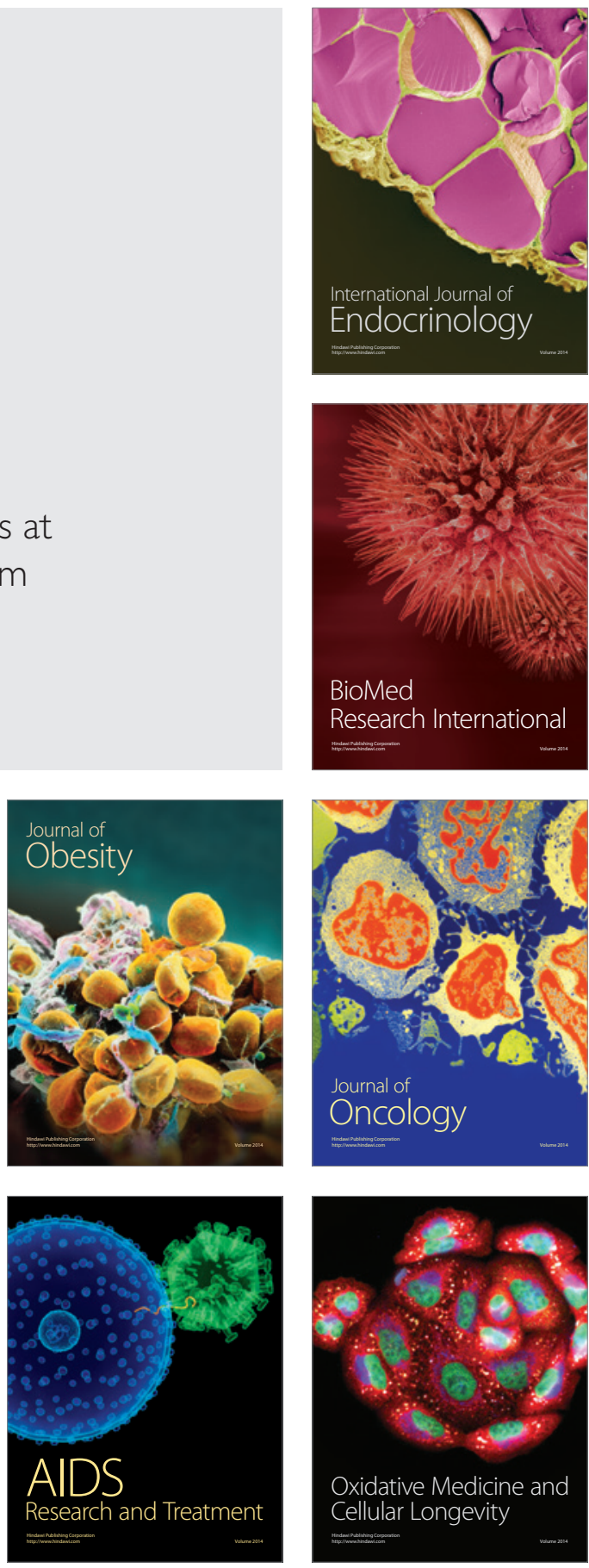